\title{
Iodine status and its determinants in subpopulation of pregnant women in rural Central India
}

\author{
Surekha A. Tayade*, Shakuntala Chhabra
}

Department of Obstetrics and Gynecology, Mahatma Gandhi Institute of Medical Sciences, Sewagram, Wardha, Maharashtra, India

Received: 13 December 2017

Accepted: 08 January 2018

*Correspondence:

Dr. Surekha A. Tayade,

E-mail: stayade@mgims.ac.in

Copyright: (c) the author(s), publisher and licensee Medip Academy. This is an open-access article distributed under the terms of the Creative Commons Attribution Non-Commercial License, which permits unrestricted non-commercial use, distribution, and reproduction in any medium, provided the original work is properly cited.

\section{ABSTRACT}

Background: There is an increased demand for iodine and thyroid hormones, in pregnancy starting from the early weeks of pregnancy suggesting that there may be a need for additional supplements of iodine in high risk population to prevent iodine deficiency and its associated disorders. Hence this study was undertaken to determine the iodine status and its determinants in a subpopulation of pregnant women from a rural area of Central India.

Methods: A hospital based, cross-sectional, observational study was carried out among pregnant women seeking antenatal care at Kasturba Hospital of MGIMS, Sewagram, a rural tertiary care institute in central India. Information was collected about demographic variables, use of iodized salt, iodine rich food and goitrogens as part of diet and other determinants. Spot urine samples were obtained, and assessment of urine iodine concentration was done by using Sandell-Kolthoff reaction.

Results: Among 250 pregnant women of first trimester, iodine deficiency (ID) was present in $11.8 \%$, of which $59.25 \%$ had mild deficiency, $33.33 \%$ moderate deficiency and $7.4 \%$ severe deficiency. More women with iodine deficiency were of higher age, had less formal education and belonged to lower middle and lower economic class. Higher number of women with iodine deficiency had family history of thyroid disorders compared to iodine sufficient (18.51\% versus $5.58 \%$ ), more iodine deficient commonly had goitrogens (cabbage, cauliflower, radish, sweet potato, soya etc) as part of their meals $(77.77 \%$ versus $68.60 \%)$, lesser women with ID ate iodine rich food (fish, milk yoghurt, bread) $(18.51 \%$ versus $68.60 \%)$ and fewer of them used iodized salt during food preparation $(25.92 \%$ versus $69.95 \%)$ compared to iodine sufficient, with a significant difference.

Conclusions: Iodine deficiency is prevalent in pregnant women in this geographic region of central India. Age, low socioeconomic status, lack of education, family history, low intake of iodized salt and iodine rich food and more consumption of goitrogenic food as part of diet are risk factors. Appropriate health education, promoting use of iodized salt, quality assurance of universal salt iodization by household survey and screening in high risk group is suggested.

Keywords: Iodine deficiency, Iodine deficiency determinants, Iodine status, Pregnant women

\section{INTRODUCTION}

Iodine is an essential micronutrient during pregnancy and has a vital role to play in the synthesis of thyroid hormone. Disorders caused by severe iodine deficiency before or during pregnancy range from decreased fertility to trophoblastic or embryonic damage, miscarriage, stillbirth or increased infant mortality, cretinism, congenital abnormalities, and psychomotor defects. ${ }^{1}$ Severe deficiency causes both maternal and fetal hypothyroidism and is associated with poor obstetric outcomes like spontaneous abortion, prematurity, and stillbirth. ${ }^{2}$ 
Zimmerman has documented the effect of iodine insufficiency on fetal neurodevelopment and fetal growth restriction (FGR) or low birth weight (LBW), less is known about preterm birth (PTB) or preeclampsia. ${ }^{3}$ Monitoring the iodine status in subpopulations of women of reproductive age group, pregnant women and school going children is of special importance to plan appropriate interventions.

With substantial progress in reducing iodine deficiency (ID), total number of countries with adequate intake increased from 67 to 116 between 2003 and $2014 .{ }^{4}$ Steady progress is seen in Europe, Asia and Western Pacific and minimal recent progress in Africa. ${ }^{5}$ European countries lacking specific iodine prophylaxis are also mildly deficient. ${ }^{6}$ At least 1,572 million people worldwide are at risk of IDD and 655 million of these are affected by goitre mostly in developing countries but also in Europe., ${ }^{7,2}$ Globally, around $29.8 \%$ of South Asian countries are estimated to have insufficient iodine intakes. ${ }^{8}$ Consumption of few dairy products/seafood and large amounts of goitrogenic foods has led to dietary iodine insufficiency in India, with 71 million affected. ${ }^{9}$ Additionally, high rainfall/flooding with mineral depletion makes Indian soil iodine deficient. ${ }^{10}$ National Iodine Deficiency Disorders Control Program (NIDDCP) has been a success story, but iodine status has seldom been considered in pregnancy, with few studies focusing on sub-populations thus, iodine deficiency prevails in some regions. ${ }^{11-13}$ With the ban on non- iodized salt, iodized salt is available in India, still its iodization and impact is unreliable partly due to access. ${ }^{13}$ As facilities determining the urinary iodine concentration are limited to regional public health laboratories, in India, studies investigating iodine in pregnancy are scarce, hence this study was undertaken with the purpose to determine the iodine status in pregnant women especially in the rural population of central India to identify the pattern of iodine levels during pregnancy and generate data to inform policy makers regarding appropriate interventions.

\section{METHODS}

\section{Study design and study site}

A hospital based, cross sectional, observational study was conducted in the Kasturba Hospital, placed in rural eastern Maharashtra in central India. Kasturba Hospital is attached to Mahatma Gandhi Institute of Medical Sciences, Sewagram, Wardha, a tertiary care referral centre serving underprivileged rural masses.

\section{Study population and ethical considerations}

250 consenting women with singleton pregnancy, attending antenatal clinic at Kasturba Hospital were recruited in first trimester. Women with multiple pregnancy, known thyroid disorders and factors affecting urinary iodine concentration were excluded. Ethical approval was sought from institutional ethical committee, informed written consent was obtained, and the research was conducted with no financial burden to the participant.

\section{Study Tool}

Demographic information, relevant obstetric and dietetic history was obtained in a pretested, validated questionnaire. Use of iodized salt, goitrogens in food (cabbage, cauliflower, radish, sweet potato, soya used at least once a week), iodine rich food (milk, yoghurt, bread, fish/other sea food) was considered in dietetic history. Socioeconomic status was classified using Modified Prasad's classification as upper, upper middle, middle, lower middle and lower using per capita income. Formal completed years of schooling was considered as one of the determinants.

\section{Urinary Iodine estimation}

5-7 $\mathrm{ml}$ of random urine sample was collected from study subjects in clean plastic containers. Toluene (preservative) was layered over it and the sample were labelled, refrigerated and sent to Regional Public Health Laboratory, Nagpur for estimation of urinary iodine concentration (UIC) where UIC was determined by ammonium persulphate method. The method used iodine's role as a catalyst in the reduction of ceric ammonium sulfate (yellow color) to the cerous form (colorless) in the presence of arsenious acid (Sandell-Kolthoff reaction). Small samples of urine $(0.25-0.5 \mathrm{ml})$ were digested with ammonium persulfate at $90-110^{\circ} \mathrm{C}$; arsenious acid and ceric ammonium sulfate were then added. The decrease in yellow color over a fixed time period was measured by a spectrophotometer and plotted against a standard curve constructed with known amounts of iodine. Quality assurance was done by standardization of reagents and techniques. The interpretation of UIC was done as per WHO criteria 2013 (121) wherein values below $50 \mathrm{ug} / \mathrm{l}$ was severe deficiency, 50-99 ug/l moderate deficiency, 100-149 ug/l mild deficiency, 150-250 ug/l adequate iodine, and $>250 \mathrm{ug} / \mathrm{l}$ was considered more than required.

\section{Statistical analysis}

Data was entered in a spread sheet (Excel) and analysis was done by using descriptive statistics using SPSS 17.0 version. Normal distribution of the data was examined by Kolmogorov-Smirnov test and reported as arithmetic means \pm SD, non-normally distributed data as medians (quartiles) and categorical data as numbers and percentages. The proportions were compared by chi square test and a two-level $\mathrm{P}$ value $<0.05$ was considered as significant.

\section{RESULTS}

A total of 250 participants were involved in the study with a mean age of $26.53 \pm 3.67$ years. Maximum were gravida 2 and all were from first trimester of gestation. Iodine deficiency was present in $11.8 \%$ study participants, of 
which $59.25 \%$ had mild deficiency, $33.33 \%$ moderate deficiency and $7.4 \%$ severe deficiency (Table 1 ).

Table 1: Iodine levels in study subjects.

\begin{tabular}{|llll|}
\hline Grading & $\begin{array}{l}\text { Urinary Iodine } \\
\text { concentration } \\
\text { ug// }\end{array}$ & $\mathrm{N}=250$ & $\%$ \\
\hline Severe deficiency & $<50$ & 2 & 0.8 \\
\hline Moderate deficiency & $50-99$ & 9 & 3.6 \\
\hline Mild Deficiency & $100-149$ & 16 & 6.4 \\
\hline Adequate & $150-250$ & 223 & 89.2 \\
\hline Above requirements & $>250$ & 0 & 0 \\
\hline
\end{tabular}

None below 19 years had iodine deficiency (ID), $1.25 \%$ between $20-24$ years, $14.42 \%$ between $25-29$ years, $15 \%$ below $30-34$ years and $20 \%$ above 35 years had ID. Thus, more women with iodine deficiency were of higher age (Table 2).

None from upper class had ID, 3.22\% from upper middle class, $5.76 \%$ from middle class, $22.41 \%$ from lower middle class and $15.15 \%$ from lower class had ID. More women from lower middle and lower class had ID. (Table 2). Among illiterate women, $75 \%$ had ID whereas $40 \%$, $19.67 \%$ and 1.75 of those educated upto primary, secondary or higher secondary school had ID. With education the occurrence of ID reduced (Table 2). More women with iodine deficiency had family history of thyroid disorders compared to iodine sufficient (18.51\% versus $5.58 \%$ ), higher number of iodine deficient commonly had goitrogens (cabbage, cauliflower, radish, sweet potato, soya etc) as part of their meals $77.77 \%$ versus $68.60 \%$ ), lesser women with ID ate iodine rich food ( $18.51 \%$ versus $68.60 \%$ ) and fewer of them used iodized salt during food preparation $(25.92 \%$ versus $69.95 \%)$ compared to iodine sufficient with a significant difference (Table 3).

Table 2: Demographic variables and iodine deficiency.

\begin{tabular}{|c|c|c|c|c|}
\hline \multirow{2}{*}{$\begin{array}{l}\text { Demographic } \\
\text { variables }\end{array}$} & \multirow{2}{*}{$\begin{array}{l}\text { Age in } \\
\text { years }\end{array}$} & \multirow{2}{*}{ Numbers } & \multicolumn{2}{|c|}{$\begin{array}{l}\text { Iodine } \\
\text { deficient }\end{array}$} \\
\hline & & & $\mathbf{n}$ & $\%$ \\
\hline \multirow{5}{*}{ Age in years } & Below 19 & 1 & 0 & 0 \\
\hline & $20-24$ & 80 & 1 & 1.25 \\
\hline & $25-29$ & 104 & 15 & 14.42 \\
\hline & $30-34$ & 60 & 9 & 15 \\
\hline & $>35$ & 5 & 1 & 20 \\
\hline \multirow{5}{*}{$\begin{array}{l}\text { Socioeconomic } \\
\text { status }\end{array}$} & Upper & 15 & 0 & 0 \\
\hline & $\begin{array}{l}\text { Upper } \\
\text { middle }\end{array}$ & 31 & 1 & 3.22 \\
\hline & Middle & 52 & 3 & 5.76 \\
\hline & $\begin{array}{l}\text { Lower } \\
\text { Middle }\end{array}$ & 58 & 13 & 22.41 \\
\hline & Lower & 66 & 10 & 15.15 \\
\hline \multirow{6}{*}{ Education } & Illiterate & 4 & 3 & 75 \\
\hline & Primary & 25 & 10 & 40 \\
\hline & Secondary & 61 & 12 & 19.67 \\
\hline & $\begin{array}{l}\text { Higher } \\
\text { Secondary }\end{array}$ & 114 & 2 & 1.75 \\
\hline & Graduate & 36 & 0 & 0 \\
\hline & $\begin{array}{l}\text { Post } \\
\text { Graduate }\end{array}$ & 10 & 0 & 0 \\
\hline
\end{tabular}

Table 3: Determinants of iodine deficiency.

\begin{tabular}{|c|c|c|c|c|c|c|c|}
\hline \multirow{2}{*}{ Determinants } & \multirow{2}{*}{ Value } & \multicolumn{2}{|c|}{ Iodine sufficient $\mathbf{n = 2 2 3}$} & \multicolumn{2}{|c|}{ Iodine deficient $\mathbf{n = 2 7}$} & \multirow{2}{*}{$\mathrm{X}^{2}$ value } & \multirow{2}{*}{ p-value } \\
\hline & & $\mathrm{n}$ & $\%$ & $\mathrm{n}$ & $\%$ & & \\
\hline Family history & Yes & 8 & 3.58 & 5 & 18.51 & 10.85 & 0.00098 \\
\hline Goitrogens & Yes & 153 & 68.60 & 21 & 77.77 & 0.95 & 0.32 \\
\hline Iodine rich food & Yes & 153 & 68.60 & 5 & 18.51 & 25.88 & 0.0000036 \\
\hline \multirow{3}{*}{ Iodized salt } & Yes & 156 & 69.95 & 7 & 25.92 & \multirow{2}{*}{34.06} & \multirow{2}{*}{0.000001} \\
\hline & No & 22 & 9.86 & 13 & 48.14 & & \\
\hline & $\begin{array}{l}\text { Don't } \\
\text { know }\end{array}$ & 34 & 15.24 & 7 & 25.92 & 23 & 0.0000016 \\
\hline
\end{tabular}

Most participants, were from rural background as the study site was rural (211 (84.4\%) rural and 39 (15.6\%) urban). Among rural residents, 23 of 211, (10.90\%) and 4 of 39 $(10.25 \%)$ from urban area had ID. Thus, ID was similar in rural as well as urban population with no significant difference.

\section{DISCUSSION}

Iodine plays a central role in thyroid physiology, being both a major constituent of thyroid hormones and a regulator of thyroid gland function. ${ }^{14}$ With an increased demand for thyroid hormone and decreased iodine availability due to transfer to fetus and intensified urinary losses, maintaining a euthyroid state in pregnancy is a challenge for the thyroid gland. ${ }^{15}$ Iodine deficiency (ID) can result in overt hypothyroxinemia, goiter, and the spectrum of iodine deficiency disorders (IDD). ${ }^{16}$ The global iodine status has improved markedly, but still 1.88 billion people are estimated to have insufficient intake and about 41 million new-borns /year remain unprotected from the consequences of brain damage associated with ID. . $^{8,17}$ 
However, scarce data exists for women of reproductive age and for pregnant women at national or sub-national level in most countries. ${ }^{18}$ Thus, this study was undertaken to determine the iodine status in pregnant women of rural area and suggest appropriate interventions.

In global prevalence data, India shows adequate iodine nutrition with a urinary iodine concentration (UIC) of 100$299 \mu \mathrm{g} / \mathrm{L}$, however, subnational data may not reflect regional differences very well. A review of Indian studies revealed significant ID in pregnant women suggesting that UIC monitoring in pregnancy be a vital component of the National program on control of IDD and highlighting the need for national level representative surveys. ${ }^{19,20}$ In the present study too, $11.8 \%$ pregnant women had ID.

Dietary iodine insufficiency is common in India, with an estimated total of 71 million affected. ${ }^{9}$ Two cross-sectional studies from Rajasthan, revealed a median UIC of 127 $\mathrm{ug} / \mathrm{L}$ in and $118 \mathrm{ug} / \mathrm{L}$ in pregnant women of $>28$ weeks of gestation. Among Indian tribal women, Menon et al found a median UIC of 106 and $71 \mathrm{mg} / \mathrm{l}$ at 17 and 34 weeks of pregnancy, respectively. ${ }^{23}$ In contrast, Lean et al in Pune, Maharashtra reported an adequate median UIC of 203 and $211 \mathrm{ug} / \mathrm{l}$ at 17 and 34 weeks respectively, implying that ID is unlikely in this population. ${ }^{24}$ This difference from different areas of the same country highlights the geographical variation which may be due to cultural/dietary habits, availability of iodine fortified products, and proximity to the sea and access to fish/seafood.

Various studies have revealed linear correlation between maternal age and UIC. In the present study as the age increased the occurrence of ID was more. Bath found a weak correlation between age and iodine-to-creatinine ratio at 12 weeks in a linear regression model while Wei $\mathrm{Z}$ also found positive correlation (b1/4 0.007, P-0.001). ${ }^{25,26}$ Zoysa et al reported that women $\leq 25$ years had significantly lower UIC compared to $\geq 25$ years. $^{27}$ Ghassabian et al too found age as a covariate and Menon et al reported that with 1 year increase in age, UIC decreased by $5 \% .^{28,23}$

Iodine sufficient were better formally educated than deficient, and illiteracy was more commonly seen in ID in the present study. Bath et al too found a positive correlation between education and iodine status and reported that with increased education there was knowledge about iodine containing food and food products, adequate and appropriate consumption of iodized salt and normal iodine status in pregnancy. ${ }^{25}$ Ghassabian et al found that education status had a positive effect on UIC. ${ }^{28}$ Contents of meals are dependent on economic status so socioeconomic status does affect the iodine status. Foods such as milk, eggs and bread are good sources of iodine, cow's milk being considered important and associations between low intake of milk and low UIC has been reported. ${ }^{29,25}$ Due to the high iodine concentration in seawater and seaweed, populations that live near the sea and frequently eat seafood usually ingest more than double the amount of iodine ingested by other populations. ${ }^{30,31}$ Thus, a higher percentage of women belonging to lower middle and lower class had ID. A family history of TD, increases risk for further developing TD with an etiology of ID. The risk is slightly greater if one has a first-degree relative (mother, sister, and daughter) with TD. ${ }^{32}$ However, others report that a positive family history of any form of TD may not be associated with increased risk of developing ID or hypothyroidism. ${ }^{33}$ The present study found a positive correlation.

National Coverage Evaluation Survey 2011, has revealed that $91 \%$ of households had access to iodized salt, $71 \%$ consumed adequately iodized salt and $9 \%$ consumed salt with no iodine; with wide rural urban variation $(83.2 \%$ in urban versus $66.1 \%$ in rural areas) and across different States/Union territories (UT). ${ }^{31}$ Government of India in 1997 imposed a ban on the storage and sale of non-iodized salt and by 2000 all UTs and states except Kerala initiated it. In Maharashtra, the ban was partial. In Maharashtra, $77.4 \%$ households used iodized salt, $14 \%$ used inadequately iodized salt and $8.6 \%$ used non- iodized salt. ${ }^{34}$ In the present study pregnant women with ID had poor intake of iodized salt. Maharashtra government may seriously think about imposing the ban completely and consider increasing the fortification of salt from $15 \mathrm{ppm}$ to $20 \mathrm{ppm}$ as the need for iodine during pregnancy increases rapidly. Fortification of alternative food for consumption by pregnant women may also be thought of.

Goitrogens are substances that disrupt the production of thyroid hormones by interfering with iodine uptake in the thyroid gland triggering the pituitary to release $\mathrm{TSH}$, which then promotes the growth of thyroid tissue, eventually leading to goiter. ${ }^{10}$ These, if consumed in considerable quantities may contribute to development of goiter but it is difficult to incriminate them as etiologic factors in vast majority of goitrous patients. ${ }^{35}$ In the present study, there was an overall increased consumption of goitrogenic food in study participants. This may be due to overall diet pattern of this rural area favouring vegetables.

In the present study, there was overall low consumption of iodine rich food in women with ID. Many Japanese eat seaweed and make soup stock from kelp on a daily basis, and in fact it is widely believed in the Japanese society that seaweed intake is good for pregnancy. ${ }^{17,36}$ In U.S, the common sources of iodine are iodized salt, dairy products, breads and seafood and thus adequate iodine was maintained. ${ }^{37}$ In Australia, mandatory use of iodized salt $(25-65 \mathrm{mg} / \mathrm{kg})$ by bread manufacturers and a daily supplement intake of $150 \mu \mathrm{g}$ of iodine by pregnant women were recommended by the National Health and Medical Research Council. ${ }^{38}$ Pregnant women in New Zealand are supplemented with iodized salt in bread to achieve adequate iodine intake. ${ }^{39}$ Present study findings also recommend fortification of alternative foods like wheat flour or bread to provide adequate iodine. 


\section{CONCLUSION}

In this geographic region of rural central India, $11.8 \%$ pregnant women representing general antenatal population had iodine deficiency (ID). Higher age and higher gravidity were risk factors for ID and it is suggested that older pregnant women and women with high gravidity should be evaluated for ID. Similar occurrence of ID was detected in rural and urban population, suggesting no difference in strategies for rural and urban population. Economic class affected ID as more women with ID were from lower middle and lower economic class, maybe they need more thrust for screening and appropriate intervention.

Good education affected iodine status. Better female literacy would improve the iodine intake and life style which later is likely to affect the happenings during pregnancy. Family history being an important risk factor, it is suggested that pregnant women with family history of TD should undergo complete evaluation for ID. There was overall high use of goitrogenic food as part of meals in most study participants and iodine deficient consumed iodized salt for food preparation in lesser numbers. It is suggested that there should be particular focus, in ensuring appropriate iodization of salt with respect to increased demand for iodine in pregnancy and ensure use. Fortification of other foods like wheat flour and bread is also suggested.

Maharashtra government may rethink about imposing a complete ban on non-iodized salt and promote universal salt iodization particularly in areas of ID. Household survey for detecting ID should be intensified in this geographic region and focus should be on universal coverage and quality of iodized salt. Health education regarding goitrogenic food and its alternatives and advantage of iodine rich food in the community are suggested and more research is required in this aspect.

\section{ACKNOWLEDGMENTS}

Authors acknowledge the support provided by faculty and postgraduates of Department of Obstetrics and Gynaecology and administrative authorities of Mahatma Gandhi Institute of Medical Sciences, Sewagram. Authors also acknowledge the participants for agreeing to be a part of this study.

Funding: Mahatma Gandhi Institute of Medical Sciences, Sewagram, Wardha, India

Conflict of interest: None declared

Ethical approval: The study was approved by the Institutional Ethics Committee

\section{REFERENCES}

1. Ghirri P, Lunardi S, Boldrini A. Iodine Supplementation in the Newborn. Nutrients. 2014;6(1):382-90.
2. WHO. Assessment of iodine deficiency disorders and monitoring their elimination: a guide for programme managers. Geneva: WHO; 2007.

3. Zimmermann MB. Iodine deficiency in pregnancy and the effects of maternal iodine supplementation on the offspring: a review. 2008;89(2):668S-72S.

4. Zimmermann MB, Andersson M. Update on iodine status worldwide. Curr Opin Endocrinol Diabetes Obes. 2012;19(5):382-7.

5. Pearce SHS, Brabant G, Duntas LH, Monzani F, Peeters RP, Razvi S. ETA guideline: management of subclinical hypothyroidism. Eu Thyroid J. 2013;2(4):215-28.

6. Vitti P, Delange F, Pinchera A, Zimmermann M, Dunn JT. Europe is iodine deficient. Lancet. 2003;361(9364):1226.

7. Bernal J. Thyroid hormone receptors in brain development and function. Nature Clin Practice Endocrinol Metab. 2007;3(3):249-59.

8. Andersson M, Karumbunathan V, Zimmermann MB. Global iodine status in 2011 and trends over the past decade. J Nutr. 2012;142(4):744-50.

9. Kochupillai N, Mehta M. Iodine deficiency disorders and their prevention in India. Reviews in Endocrine and Metabolic Disorders. 2008;9(3):237.

10. Kapil U. Health consequences of iodine deficiency. Sultan Qaboos Univ Med J. 2007;7(3):267-72.

11. Chakraborty I, Chatterjee S, Bhadra D, Mukhopadhyaya B. Iodine deficiency disorders among the pregnant women in a rural hospital of West Bengal. Ind J Med Res. 2006;123(6):825.

12. Rendina D, De Filippo G, Mossetti G, Zampa G, Muscariello R, Benvenuto $\mathrm{G}$, et al. Relationship between metabolic syndrome and multinodular nontoxic goiter in an inpatient population from a geographic area with moderate iodine deficiency. J Endocrinol Investigation. 2012;35(4):407-12.

13. Kapil U. Presence of severe iodine deficiency in areas with adequate salt iodization. Indian $\mathrm{J}$ Pediatr. 2011;78(10):1299-300.

14. Charoenratana C, Leelapat $\mathrm{P}$, Traisrisilp K, Tongsong T. Maternal iodine insufficiency and adverse pregnancy outcomes. Maternal and child nutrition. 2016;12(4):680-7.

15. Glinoer D. The regulation of thyroid function during normal pregnancy: importance of the iodine nutrition status. Best Practice and Research Clinical Endocrinology and Metabolism. 2004;18(2):133-52.

16. Glinoer D. The importance of iodine nutrition during pregnancy. Public Health Nutr. 2007;10(12A):15426.

17. Jaikrishna N. Effect of iodine supplementation in Indian pregnant women on maternal and newborn thyroid function and cognitive development: Wageningen University; 2015.

18. Caldwell KL, Makhmudov A, Ely E, Jones RL, Wang RY. Iodine status of the US population, National Health and Nutrition Examination Survey, 2005-2006 and 2007-2008. Thyroid. 2011;21(4):419-27. 
19. Yadav K, Srivastava R, Badhal S, Palanivel C, Pandav CS, Karmarkar MG. Iodine nutrition of pregnant women in India: evidence of significant iodine deficiency. Indian J Med Special. 2012;3:49-54.

20. Pandav CS, Yadav K, Srivastava R, Pandav R, Karmarkar MG. Iodine deficiency disorders (IDD) control in India. Indian J Med Res. 2013;138(3):41833.

21. Ategbo E-A, Sankar R, Schultink W, van der Haar F, Pandav CS. An assessment of progress toward universal salt iodization in Rajasthan, India, using iodine nutrition indicators in school-aged children and pregnant women from the same households. Asia Pacific J Clin Nutr. 2008;17(1):56-62.

22. Singh MB, Fotedar R, Lakshminarayana J. Micronutrient deficiency status among women of desert areas of western Rajasthan, India. Public Health Nutrition. 2009;12(05):624-9.

23. Menon KC, Skeaff SA, Thomson CD, Gray AR, Ferguson EL, Zodpey S, et al. The effect of maternal iodine status on infant outcomes in an iodine-deficient Indian population. Thyroid. 2011;21(12):1373-80.

24. Lean MIFA, Lean MEJ, Yajnik CS, Bhat DS, Joshi $\mathrm{SM}$, Raut DA, et al. Iodine status during pregnancy in India and related neonatal and infant outcomes. Public Health Nutrition. 2013;17(6):1353-62.

25. Bath SC, Furmidge-Owen VL, Redman CW, Rayman MP. Gestational changes in iodine status in a cohort study of pregnant women from the United Kingdom: season as an effect modifier. Am J Clin Nutr. 2015;101(6):1180-7.

26. Wei Z, Wang W, Zhang J, Zhang X, Jin L, Yu X. Urinary iodine level and its determinants in pregnant women of Shanghai, China. $\mathrm{Br} \mathrm{J}$ Nutr. 2015;113(9):1427-32.

27. Zoysa D, Hettiarachchi E, Liyanage M, Chandrani. Urinary iodine and thyroid determinants in pregnancy: a follow up study in Sri Lanka. BMC Pregnancy and Childbirth. 2016;16(1):303.

28. Ghassabian A, Steenweg-de Graaff J, Peeters RP, Ross HA, Jaddoe VW, Hofman A, et al. Maternal urinary iodine concentration in pregnancy and children's cognition: results from a population-based birth cohort in an iodine-sufficient area. BMJ Open. 2014;4(6):e005520.
29. World Health Organization WHO global database on iodine deficiency. Available at http://www.who.int/vmnis/database/iodine/en Accessed 7 May 2011.

30. Smyth PPA, O'Herlihy C. Dietary iodine intake in pregnancy. Ir Med J. 2006;99.

31. Institute of Medicine (US) Panel on Micronutrients. Dietary Reference Intakes for Vitamin A, Vitamin K, Arsenic, Boron, Chromium, Copper, Iodine, Iron, Manganese, Molybdenum, Nickel, Silicon, Vanadium, and Zinc. Washington, DC; National Academy Press; 2001:258-89.

32. Araujo DB, Barone B, Melleti NFT, Dantas JR, Oliveira MMdS, Zajdenverg L, et al. Thyroid disorders are common in first-degree relatives of individuals with type 1 diabetes mellitus. Arch Endocrinol Metabol. 2015;59:112-5.

33. Bensenor IM, Olmos RD, Lotufo PA. Hypothyroidism in the elderly: diagnosis and management. Clinical Interventions in Aging. 2012;7:97-111.

34. UNICEF. Coverage evaluation survey 2009, All India Report. Ministry of Health and Family Welfare, Government of India, New Delhi; 2010. 2011.

35. Bajaj JK, Salwan P, Salwan S. Various possible toxicants involved in thyroid dysfunction: a review. J Clin Diagc Res JCDR. 2016;10(1):FE01-FE3.

36. Zava TT, Zava DT. Assessment of Japanese iodine intake based on seaweed consumption in Japan: a literature-based analysis. Thyroid Res. 2011;4:14.

37. Leung AM. Thyroid function in pregnancy. $J$ of Trace Elements in Medicine and Biology: Organ of The Society for Minerals and Trace Elements. (GMS). 2012;26(0):137-40.

38. National Health and Medical Research Council, Australia. Iodine supplementation for pregnant and breastfeeding women. Canberra, Australia. 2010.

39. Evans CS. Iodine status in pregnant New Zealand women: Are intakes and recommendations adequate? (Thesis, Master of Science). University of Otago. 2015. Available at http://hdl.handle.net/10523/5633.

Cite this article as: Tayade SA, Chhabra S. Iodine status and its determinants in subpopulation of pregnant women in rural Central India. Int J Reprod Contracept Obstet Gynecol 2018;7:665-70. 